\title{
Therapeutic potential of adipose derived mesenchymal stem cells in regeneration of gastric ulcer in rats
}

\author{
Original \\ Article
Ahmed Nour El Din El Kasaby', Mamdouh Abd El Halim Ghaly ${ }^{l}$, Asmaa Abd El Monem Abo Zeid ${ }^{2}$, and Ibrahim Mohammed Fayed ${ }^{1}$ \\ ${ }^{1}$ Department of Histology \& Cell biology, Faculty of Medicine, Al Azhar University, Egypt \\ ${ }^{2}$ Department of Histology \& Cell biology, Faculty of Medicine, Ain Shams University, Egypt
}

\begin{abstract}
Background and objectives: Adipose tissue is an abundant and easily accessible tissue for obtaining multipotent stem cells that harbor similar phenotypes to bone marrow mesenchymal stem cells. This study aimed to demonstrate the effect of adiposederived mesenchymal stem cells (AD-MSCs) on repairing the aspirin-induced gastric ulcer (GU).

Materials and Methods: The gastric ulcer in rats was induced by oral dose of $100 \mathrm{mg} / \mathrm{kg}$ aspirin for 3 days. AD-MSCs isolated from male rats were transplanted into female rats via tail vein injection. Healing of the GU was monitored histologically. Homing of the in vivo administration of MSCs was assessed by PCR detection of SRY gene and immunohistochemical detection of CD44 in gastric mucosa.

Results: At 72 hours after AD-MSCs transplantation, there was complete restoration of the fundic glands with marked reduction in inflammatory cellular infiltrate and a significant increase in the mean value of optical density of PAS positive area $(\mathrm{P}<0.05)$. The mean number of CD44 positive cells in the gastric mucosa was significantly increased $(\mathrm{P}<0.05)$. SRY -specific gene of Y chromosome was detected in female rat gastric mucosa.

Conclusions: In vivo transplantation of AD-MSCs accelerate healing of GU in a rat model of gastric injury.
\end{abstract}

Key Words: Adipose derived mesenchymal stem cells, CD44, gastric ulcer, SRY gene

Revised: 24 January 2018 Accepted: 25 March 2018

Corresponding Author: Asmaa Abd El Monem Abo Zeid, Department of Histology \& Cell Biology, Faculty of Medicine, Ain Shams University, Abbasia, Cairo, Egypt Tel.: +20-1005417879, E-mail: asmaazied@yahoo.com

ISSN: 2536-9172, Vol.1, No.2

\section{INTRODUCTION}

Peptic ulcer is a major health hazard and is a leading cause of morbidity and mortality among different socioeconomic classes ${ }^{[1]}$. Peptic ulcer is characterized by mucosal damage with subsequent direct exposure to pepsin and gastric acid secretion. It usually occurs in the stomach and proximal duodenum ${ }^{[2]}$.

The incidence of ulcer has been shown to be increasing considerably because of the widespread and long-term use of non-steroidal anti-inflammatory drugs (NSAIDs) $)^{[3]}$.

Gastric ulcers (GU) resulting from aspirin (acetylsalicylic acid) intake require medical and sometimes surgical interventions. Medications include inhibition of gastric acid secretion by $\mathrm{H} 2$ receptor antagonists or proton pump inhibitors as well as antibiotics for elimination of $\mathrm{H}$. pylori ${ }^{[4]}$. However, these medications are not completely effective and produce many adverse effects such as gynecomastia, acute interstitial nephritis, thrombocytopenia, nephrotoxicity and hepatotoxicity[5]. Therefore, an alternative new therapeutic strategy is needed for injured gastric mucosa.
Several reports indicated that bone marrowmesenchymal stem cells (BM-MSCs) contributed to the formation of gastrointestinal tissues and played a key role in the healing of gut injuries. Furthermore, they could stimulate angiogenesis, enhance microcirculation in the gastric mucosa, and accelerate the healing rate of the gastric mucosa in a rat model of $\mathrm{GU}^{[6]}$. MSCs can engraft in injured stomach ${ }^{[7]}$ and in some cases, are thought to acquire epithelial characteristics ${ }^{[8]}$. This also may explain the several properties of MSCs that include their differentiative, regenerative and migratory capacity, immunomodulation and paracrine activity with the secretion of angiogenic, antiapoptotic and anti-inflammatory factors ${ }^{[9]}$.

MSCs isolated from adipose tissue has been found to be easily accessible, has more proliferative capacity and more potent than BM-MSCs ${ }^{[10]}$.

The inflamed or injured tissues increased their stromal production of the glycosaminoglycans hyaluronic acid (HA). It creates a highly hydrated extracellular matrix that enhances local cellular mobilization ${ }^{[1]}$. 
The main cell surface receptor for HA is the proteoglycan CD44 ${ }^{[12]}$. CD44 performs many functions such as regulation of cell proliferation, differentiation, migration to different tissues including hematopoietic progenitor cells trafficking to the bone marrow and spleen $^{[13,14]}$. So, this study aimed to demonstrate the possible therapeutic effect of adipose-derived- MSCs (AD-MSCs) against the aspirin induced gastric ulcer in rats monitored by histological and immunohistochemical methods. Furthermore, the homing of the exogenous administrated MSCs was assessed by means of SRY gene detection and CD44 localization methods in the recipient female rat gastric mucosa.

\section{PATIENTS AND METHODS}

\section{Isolation of AD-MSCs from rats}

Fat pads around spermatic cords were isolated from three male rats (120-150 gm) under aseptic condition. The specimens were washed extensively with sterile phosphate buffer saline (PBS; Lonza, Swiss) to remove any contamination. The washed tissues were cut into small pieces $0.5 \mathrm{~mm}^{3}$ and enzymatically digested with $0.1 \%$ collagenase type-I (Sigma Aldrich, St. Louis, MO, USA) for $45-60$ minutes and incubated at $37^{\circ} \mathrm{C}$ with intermittent shaking every $10 \mathrm{~min}$. The collagenase activity was blocked by $10 \mathrm{ml}$ of fetal bovine serum (FBS). The suspension was filtered by 100 um nylon mesh and centrifuged at 1800 $\mathrm{rpm}$ for $10 \mathrm{~min}$ at $25{ }^{\circ} \mathrm{C}$. Pellets were resuspended in complete medium (Dulbecco's-modified Eagle's medium (DMEM) supplemented with 10\% FBS and 1\% Penicillin/ Streptomycin) and incubated at $37^{\circ} \mathrm{C}$ with $5 \% \mathrm{Co}_{2}$. The medium was changed twice per week, and the cells were sub cultured when $80 \%$ confluence was reached. The third passaged cells were utilized in this study ${ }^{[15]}$.

\section{Flow cytometry analysis}

The third passaged AD-MSCs were harvested using trypsin/EDTA digestion and suspended at a concentration of $2 \times 10^{5}$ cells $/ 100 \mu \mathrm{l}$ of PBS. The cells were incubated with fluorescein isothiocyanate (FITC)-conjugated anti-rat CD 45 and CD 90 monoclonal antibodies (Thermo Fisher Scientific, USA). The cells were washed in PBS, fixed in $1 \%$ formaldehyde and analyzed using a FACS Calibur Flowcytometer (BD Biosciences). Data were analyzed by Cell Quest software ${ }^{[16]}$.

\section{Animals}

Forty adult female Wistar rats with an average weight $150-200$ gm were included in this study. They were housed in separate cages in the Medical Research Centre, Faculty of Medicine; Ain shams University. All procedures for animal care and experiments were done according to ethics committee recommendations of Ain Shams University. They were fed ad libitum and allowed free access to water.

\section{Animal grouping}

The animals were divided randomly into a control group and three experimental groups. Group1 [Control group], $\mathrm{n}=10$, each rat received a daily oral dose of $1 \mathrm{ml} 0.9 \%$ physiological saline using intra-gastric tube. Three rats were sacrificed with each experimental group. Experimental groups (induction of the gastric ulcer), $\mathrm{n}=30$, each rat received acetyl salicylic acid (aspirin) in a daily oral dose of $100 \mathrm{mg} / \mathrm{kg}$ /day dissolved in $1 \mathrm{ml}$ saline for 3 days, using intra-gastric tube. Rats were fasted for $1 / 2$-1hour before drug intake ${ }^{[17]}$. The thirty rats were divided equally into three groups: Group 2 [Aspirininduced GU], the rats were sacrificed 3 days after oral aspirin consumption. Group 3 [Recovery group], the rats were sacrificed 3 days after aspirin intake i.e. 6 days from the beginning of the experiment. Group 4 [ADMSCs treated group], each rat injected with $\left(1.5 \times 10^{6}\right)$ AD-MSCs / $0.5 \mathrm{ml}$ PBS immediately after oral aspirin consumption into the caudal vein then they were sacrificed 3 days after MSCs transplantation.

\section{Histological study}

After sacrificing the animals, the stomachs were dissected and cut along the greater curvature. The gastric mucosa was rinsed with saline to remove any contaminates. Specimens from the cardiac and fundic regions of the stomach were fixed in $10 \%$ buffered formalin solution for 24-48 hours, dehydrated in ascending grades of ethanol and embedded in paraffin. Serial sections of 5-7 micrometer thickness were cut and mounted on glass slides for histological staining. H\&E stain to examine the morphological changes and Periodic Acid Schiff's Reaction (PAS) to study the changes in the mucous secretion.

\section{Immunohistochemical staining of gastric specimens}

\section{for CD44}

For detection and counting of CD44-positive cells in the fundic glands, paraffin-embedded stomach sections were deparaffinized and rehydrated. The slides were incubated in $10 \%$ hydrogen peroxide $\left(\mathrm{H}_{2} \mathrm{O}_{2}\right)$ for 10 minutes to deactivate the endogenous peroxidase. Blocking serum was used to block the nonspecific binding sites. Then, slides were incubated with CD44 antibody (Thermo Fisher Scientific, USA). The antibody binding sites in the fundic glands were visualized by the avidin-biotin-peroxidase complex method. The nuclei were counterstained with hematoxylin ${ }^{[18]}$.

\section{Morphometric study}

The following parameters were measured:

1. Optical density of PAS reaction in PAS stained sections. 
2. The mean number of CD44-positive cells/ HPF in stomach specimens.

All parameters were measured from five different visual fields selected from five slides in each group at HPF. All the measurements were performed using the image analyzer Leica Q500 MC program in the Histology Department Faculty of Medicine Ain Shams University, where the PC was connected to an Olympus XB microscope- Japan.

\section{PCR detection of Y chromosome (SRY gene)}

Polymerase chain reaction (PCR) for the rat Y-chromosome specific SRY gene was performed from the gastric mucosa of female rats three days after AD-MSCs transplantation. The DNA was extracted from the tissue specimens with a QIAamp Tissue Kit (Qiagen, Valencia, Calif) according to the manufacturer's instructions. Amplification of DNA strands was done through thermal cycles consisted of denaturation at $95^{\circ} \mathrm{C}$, annealing at $62^{\circ} \mathrm{C}$, and elongation at $72^{\circ} \mathrm{C}$ repeated 50 times. The amplified PCR products were separated on $2 \%$ agarose gel electrophoresis, stained by ethidium bromide and visualized under the UV Trans-illumination. The sequences of oligonucleotide primers were 5'-CAT GAA CGC ATT CAT CGT GTG GTC-3'; and 5'-CTG CGG GAA GCA AAC TGC AAT TCT T-3' for SRY gene. Y chromosomes marker detected as trans-illuminated line ${ }^{[19]}$

\section{Statistical analysis}

Data obtained were tabulated \& statistically analyzed using the statistical package of social science (SPSS version 17) to evaluate the difference between the groups. Descriptive statistics were done in the form of mean and standard deviation. Mean of each group was compared to the others using the one-way analysis of variance (oneway ANOVA). The significant difference was defined as p-values $<0.05$.

\section{RESULTS}

Morphology and identification of the cultured AD-MSCs

The isolated AD-MSCs started to adhere to the plastic substrate of tissue culture flasks sporadically attaining different shapes three days after primary culture. On day five, the cells became more crowded, forming small colonies interconnecting with each other. The cells proliferated rapidly and reached $90 \%$ confluency on day seven after primary culture. The cells were passaged nearly twice per week. The cells from passage three were of homologous spindle-shaped phenotype (Figure 1). At least $98 \%$ of AD-MSCs at passage 3 were positive for CD90, a marker for thymic lymphocytes (Thy-1). In contrast, less than $1 \%$ of the cell populations were negative for CD45 (common leukocyte Ag) (Figure 2).

\section{Experimental induction of gastric ulcer}

Intragastric administration of $0.9 \%$ saline did not produce any considerable damage in the gastric mucosa as detected by histological examination. Seventy-two hours after aspirin administration, there was sloughing of the gastric epithelium as well as ulceration extending till muscularis mucosa. Exfoliated necrotic epithelial cells were found in the gastric lumen. Lumina of the fundic glands were dilated in areas adjacent to the ulcer (Figures 3A \& B). Oxyntic cells at the base of the ulcer were vacuolated. The connective tissue of the corium as well as the submucosa showed dilatation of blood vessels and extravasated inflammatory cellular infiltrate (Figure 4B).

Transplantation of AD-MSCs enhanced GU

healing

Three days after AD-MSCs administration, the gastric mucosa revealed complete reepithelization of the fundic glands but with slight dilatation in the pits and lumina of some glands. In contrast, the mucosa still showed areas of ulcers and desquamated cells were present in the lumen of stomach in group 3 that left for spontaneous recovery (Figures 3C\&D). Furthermore, the oxyntic and chief cells regained their histological structure. However, some of oxyntic cells still demonstrated vacuolation in their cytoplasm with mild leucocytic infiltration in the connective tissue corium of the mucosa of group 4 . Whereas many parietal cells in the remaining parts of the fundic glands in group 3 appeared vacuolated and pale stained. The extravasated mononuclear cellular infiltrates were heavy in the lamina propria between the fundic glands (Figures 4C\&D).

\section{PAS stained sections}

Significant reduction in the mean value of optical density of PAS reaction was noticed in group 2 (aspirininduced gastric ulcer) and group 3 (recovery group) as compared to that in the control group $(\mathrm{P}<0.05)$.

In contrast, there was a significant increase in the mean value of optical density of PAS positive area in group 4 (treated with AD-MSCs) as compared to group $3(\mathrm{P}<0.05)$ (Figure 5) (Table 1, Histogram 1)

\section{Immunohistochemical detection of CD44 positive}

\section{cells in gastric mucosa}

Figure 6 revealed many branched cells with brownish cytoplasmic reaction for CD44 with counterstained nuclei present in between bases of the fundic glands in group 4 that received AD-MSCs transplantation. In comparison with the other groups, there were no or 
few CD44 positive cells in the basal parts of the fundic glands. The mean number of CD44 positive cells in group 4 was significantly increased $(\mathrm{P}<0.05)$ as compared with group $3 ; 26.8 \pm 5.06$ vs $4.6 \pm 2.07$ (Table $1 \&$ Histogram 2).

\section{Detection of Y-chromosome-specific gene (SRY} gene) in gastric tissue of the female rats

As shown in Figure 7, male rat SRY gene could be detected in the gastric homogenates of the female rates that received AD-MSCs transplantation by PCR products of SRY gene.

Table 1: Mean values of optical density of PAS reaction and mean values of number of CD44 positive cells in gastric mucosa in all groups.

\begin{tabular}{|c|c|c|c|c|}
\hline Parameter & Group 1 & Group 2 & Group 3 & Group 4 \\
\hline $\begin{array}{l}\text { Mean values of optical } \\
\text { density of PAS reaction }\end{array}$ & $1.22 \pm 0.10$ & $1.10 \pm 0.10^{\mathrm{a}}$ & $1.17 \pm 0.11$ & $1.20 \pm 0.09^{b}$ \\
\hline $\begin{array}{l}\text { Mean values of number } \\
\text { of CD } 44 \text { positive cells in } \\
\text { gastric mucosa }\end{array}$ & $1.2 \pm 1.09$ & $2.4 \pm 1.14$ & $4.6 \pm 2.07$ & $26.8 \pm 5.06^{b}$ \\
\hline
\end{tabular}

Data are expressed as mean \pm standard deviation.

${ }^{a}$ Significant decrease compared with group $1(\mathrm{P}<0.05)$.

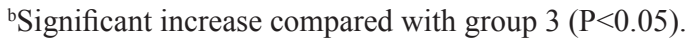

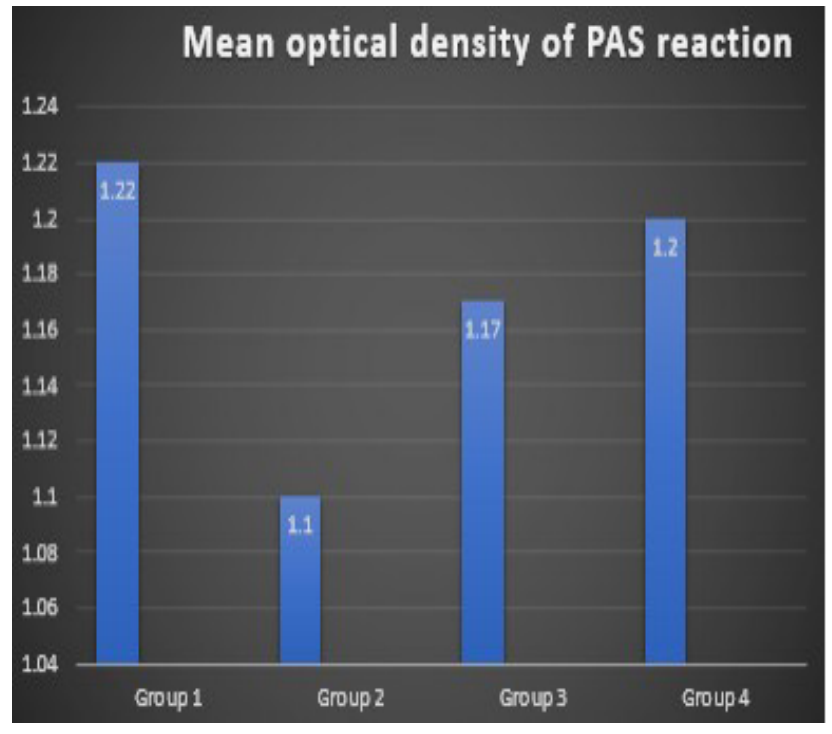

Histogram 1: Mean values of optical density of PAS reaction at the surface epithelium and mucus neck cells of gastric glands of all groups.

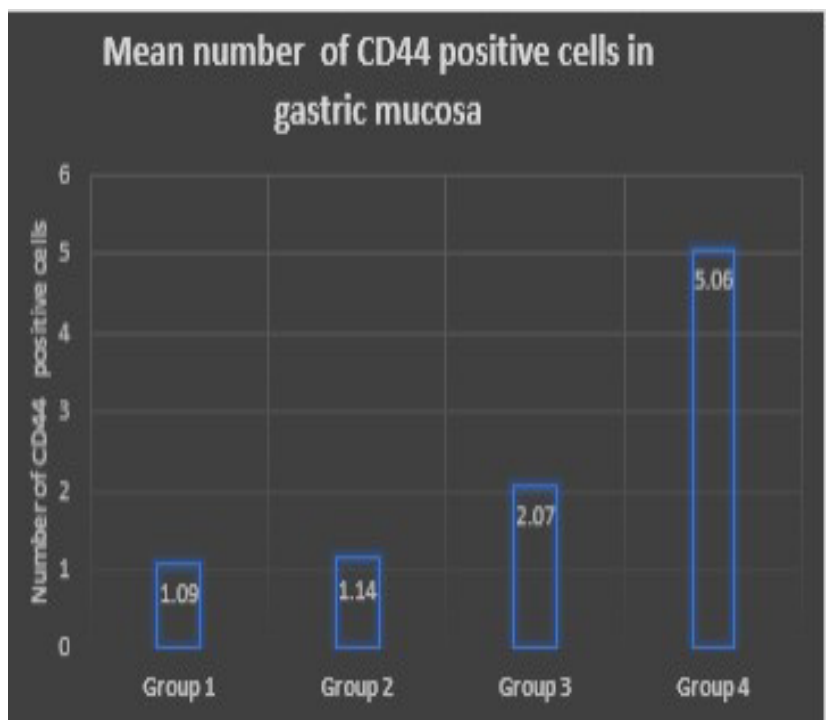

Histogram 2: Mean values of number of CD44 positive cells in bases of fundic glands of different groups. 



Fig. 1: Morphology of AD-MSCs as detected by the phase contrast microscopy. (A) On day 3 of primary culture, the AD-MSCs adhere to the plastic surface and appear with variable sizes and shapes. Some cells appear spindle shaped with long cytoplasmic processes $(\uparrow)$, others are star shaped $(*)$ and triangular shaped $(\boldsymbol{\Delta})$. (B) On day 5, the cells show granular cytoplasm with vesicular nuclei $(*)$ forming small colonies ( $\uparrow \uparrow$ ). Some cells appear binucleated $(\boldsymbol{\Lambda})$. (C) The cells reach about $85-90 \%$ confluency on day 7 of primary culture, (P0 x 400). (D) $3^{\text {rd }}$ passaged AD-MSCs appear homogenous in shape. Most of the cultured cells have fibroblastic appearance ( $\uparrow$ ) forming whorls, (P3x 200).
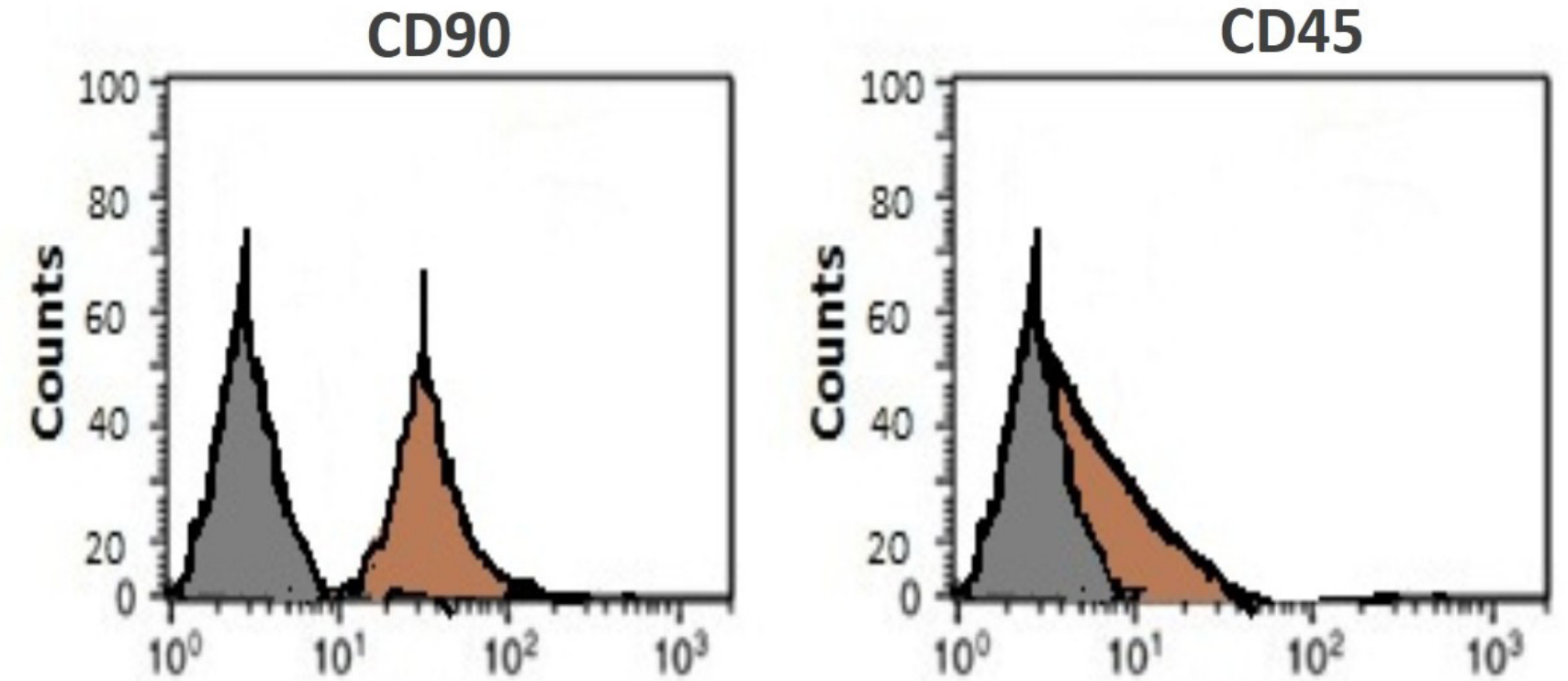

Fig. 2: Flowcytometric analysis of the AD-MSCs at passage 3. More than $98 \%$ of the cells express CD 90 , whereas they are negative for CD45. Grey curves are the results of staining with isotype-identical antibody as a negative control. 

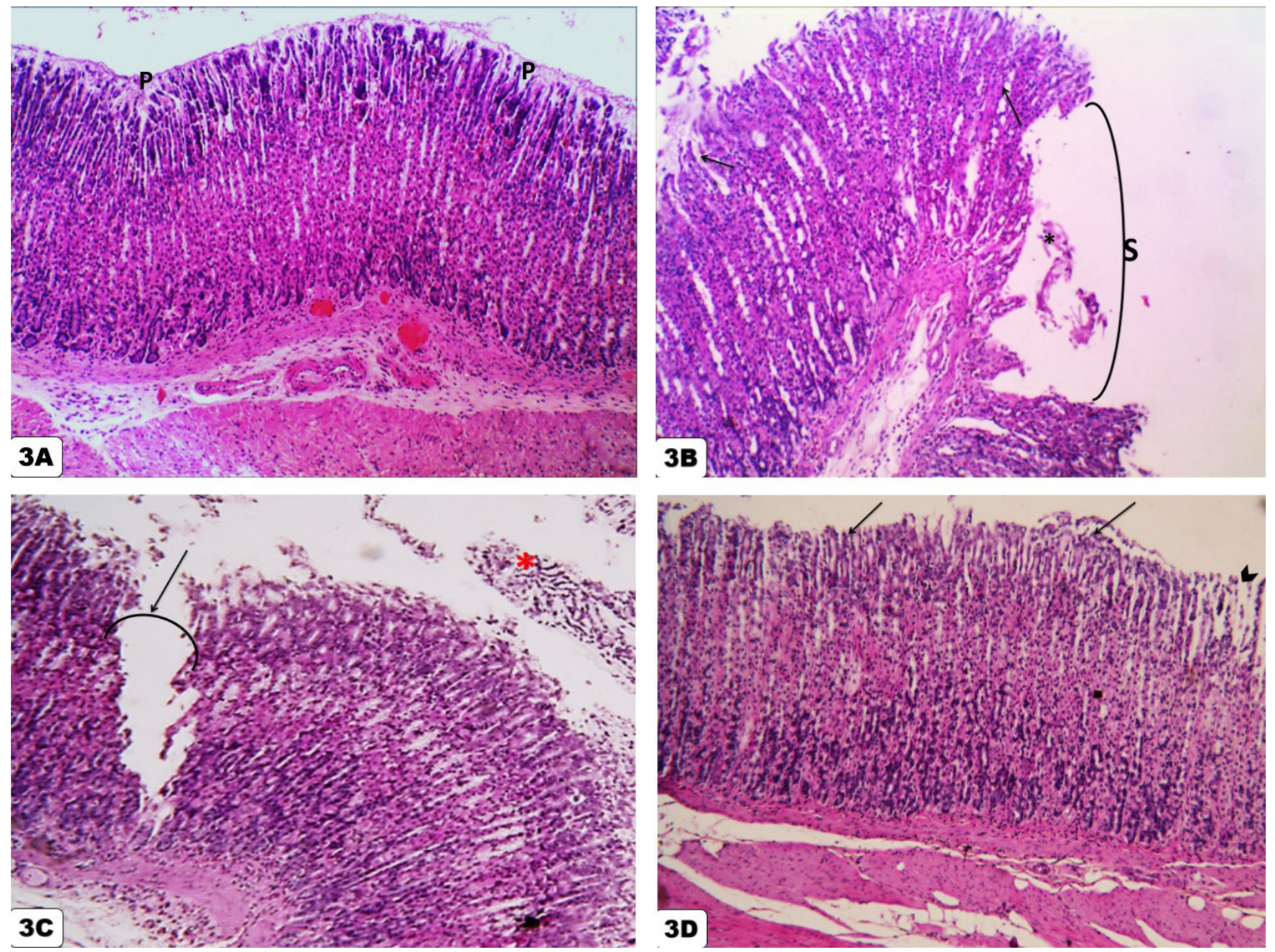

Fig. 3: (A) The control group (G1), showing normal histological features of the fundic glands and the lining cells. Glands open into the lumen by short narrow pits (P). (B) Large area of the fundic glands is sloughed (S) with presence of exfoliated cells in the lumen $(*)$ in the aspirininduced GU (G 2). The Lumina of some glands are widened ( $\uparrow$ ). (C) The fundus of the stomach of recovery group (G 3) still show smaller areas of erosions and ulcer $(\uparrow)$ with desquamated epithelial cells in the lumen $(*)$. (D) The fundic glands of the ADMSCs-treated group (G 4) showing mucosal reepithelization $(\uparrow)$. Note slight dilatation in the pits of other glands (arrowhead).

$(\mathrm{H} \& \mathrm{E}, \mathrm{x} 200)$. 

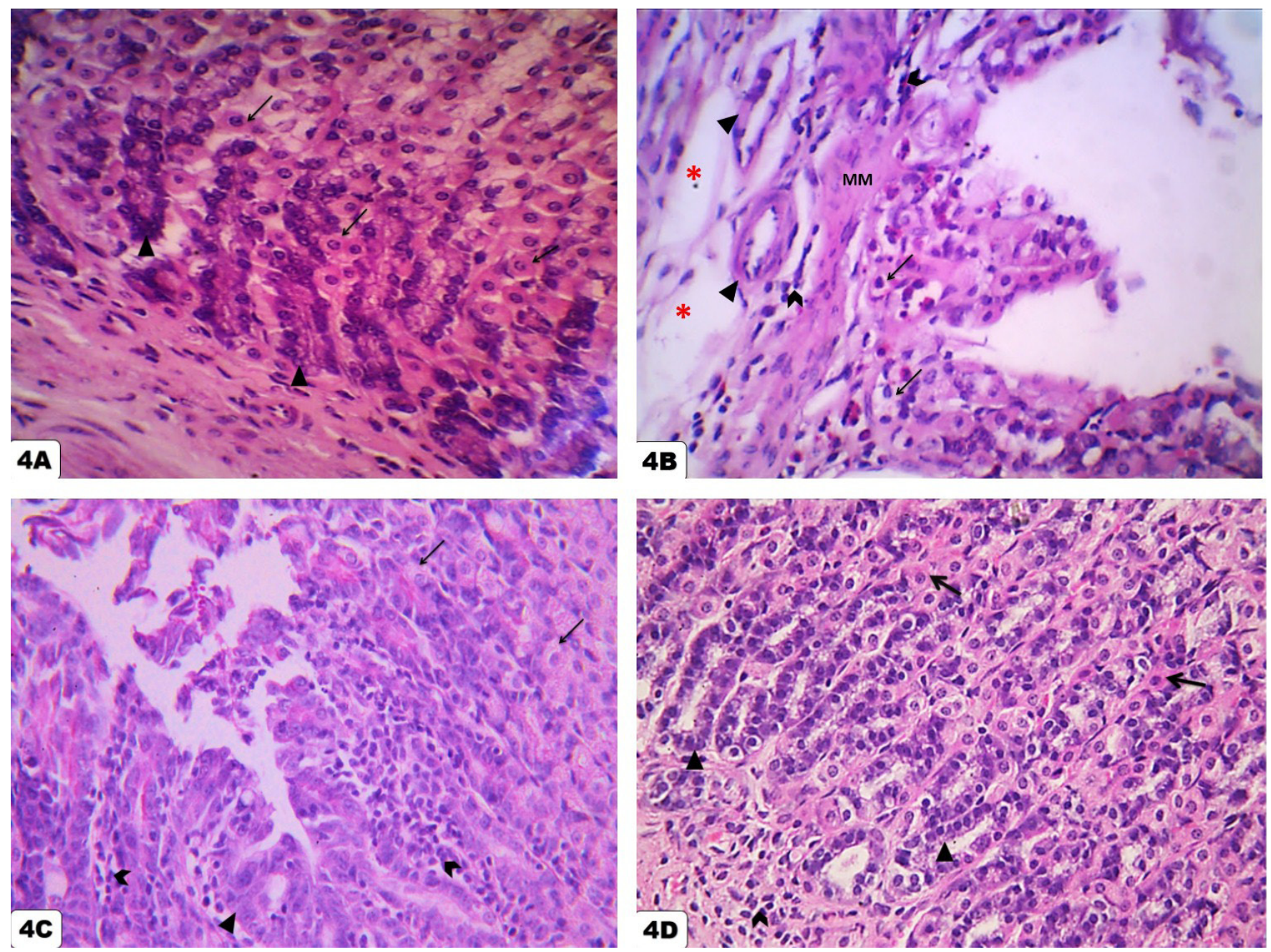

Fig. 4: (A) The parietal cells of G1 show deeply acidophilic cytoplasm with central rounded nuclei ( $\uparrow$ ). Chief cells exhibit deeply basophilic cytoplasm and basal rounded nuclei $(\boldsymbol{\Delta})$. (B) In G2, there is sloughing of the epithelium of fundic glands till muscularis mucosa (MM). Note vacuolated parietal cells $(\uparrow)$. The submucosa at the base of the ulcer reveals slightly dilated blood vessels $(\boldsymbol{\Delta})$ and edema $(*)$. Mononuclear cellular infiltration is also noticed in submucosa as well as in lamina propria (arrowheads). (C) The parietal cells of G3 appear vacuolated $(\uparrow)$ and chief cells are pale-stained $(\boldsymbol{\Delta})$. Intense leucocytic infiltration is still present in the corium of the mucosa (arrowhead). (D) The chief cells $(\boldsymbol{\Delta})$ of G4 are of normal appearance, while some of the parietal cells still have vacuolated cytoplasm $(\uparrow)$. Mild leucocytic infiltration is observed (arrowhead).

(H\&E, x400). 

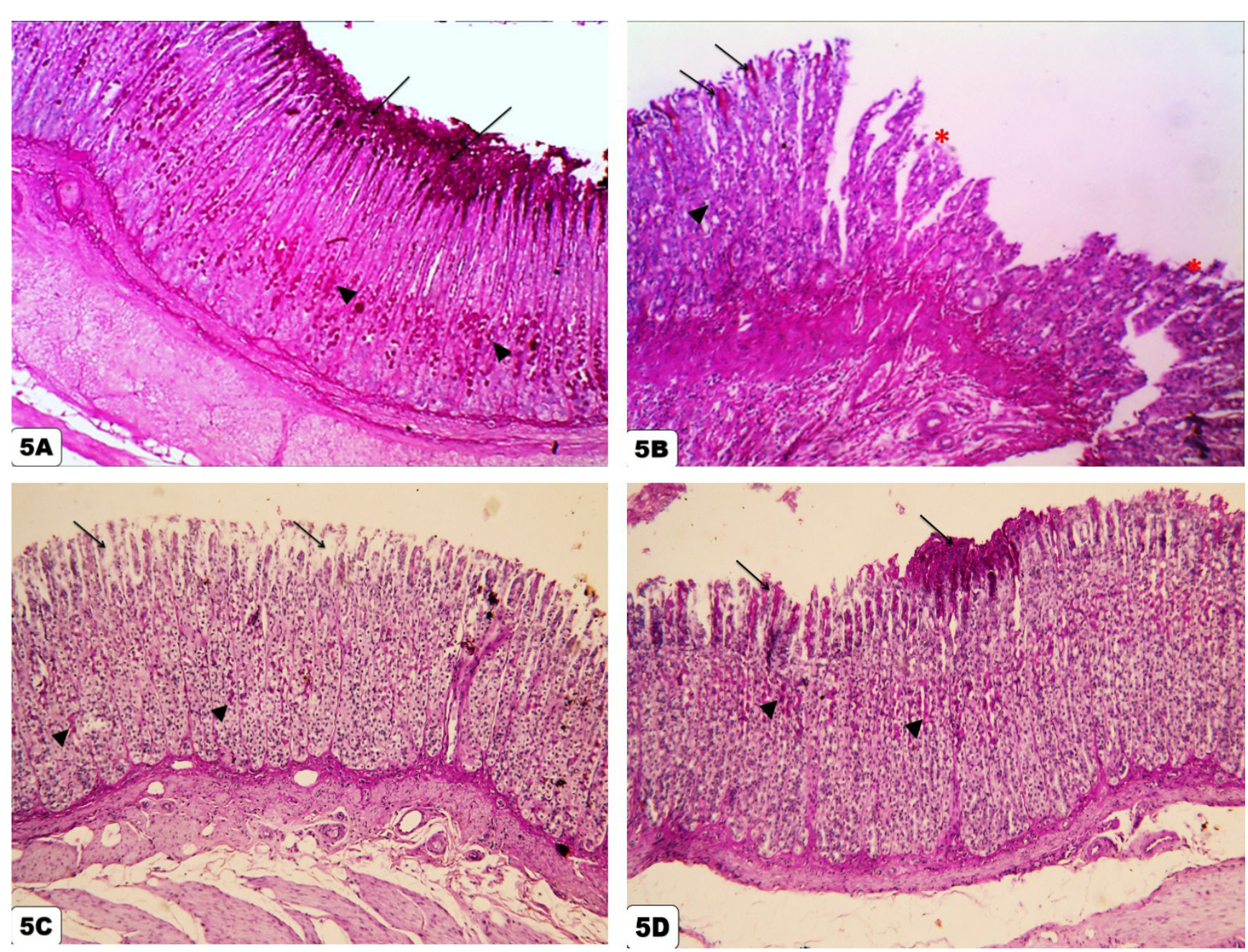

Fig. 5: (A) The fundus of the stomach of G1, showing positive PAS reaction at the surface epithelium $(\uparrow)$ and mucus neck cells of the gastric glands $(\boldsymbol{\Delta})$. (B) G2, showing loss of PAS reaction from the sloughed areas $(*)$ with weak positive PAS reaction in both surface epithelial cells $(\uparrow)$ and mucus neck cells (arrowhead) of areas adjacent to the ulcer margin. (C) G3, showing weak positive PAS reaction at mucus neck cells in some areas $(\boldsymbol{\Lambda})$. Note surface columnar epithelial cells have no PAS reaction ( $\uparrow$ ). (D) G4, showing strong positive PAS reaction at the surface epithelium $(\uparrow)$ and mucus neck cells $(\boldsymbol{\Lambda})$ in some areas.

(PAS, x 200). 

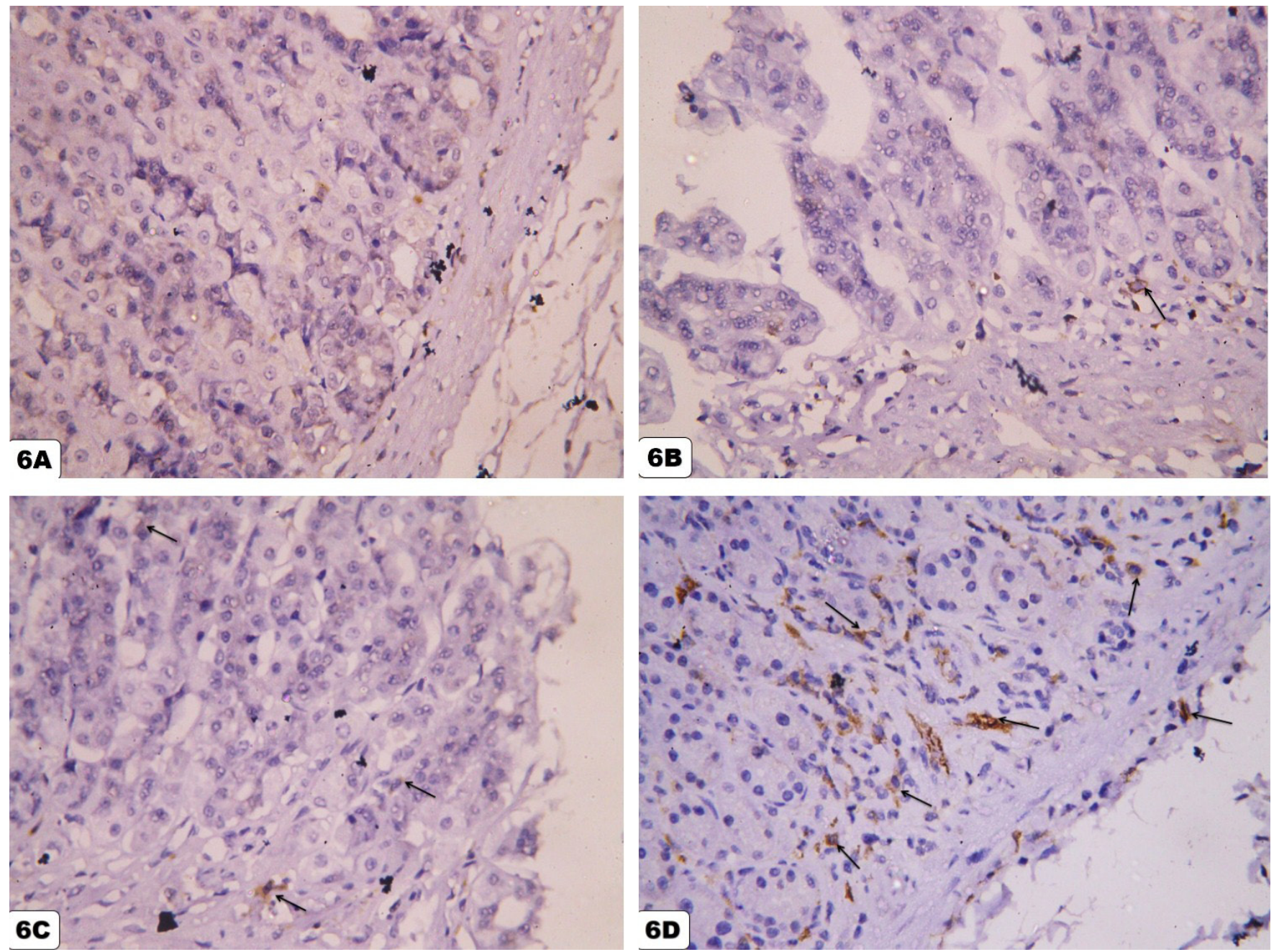

Fig. 6: (A) The bases of the fundic glands of G1 show no reaction for CD44 antibody. (B) The bases of the fundic glands of G2 show few CD44 positive cells $(\uparrow)$. (C) The bases of the fundic glands of G3 show some CD44 positive cells ( $\uparrow$ ). (D) Whereas, the bases of the fundic glands of G4 show many CD44 positive cells. They appear branched with brownish cytoplasm ( $\uparrow$ ).

(Immunostaining for CD44, x 400).

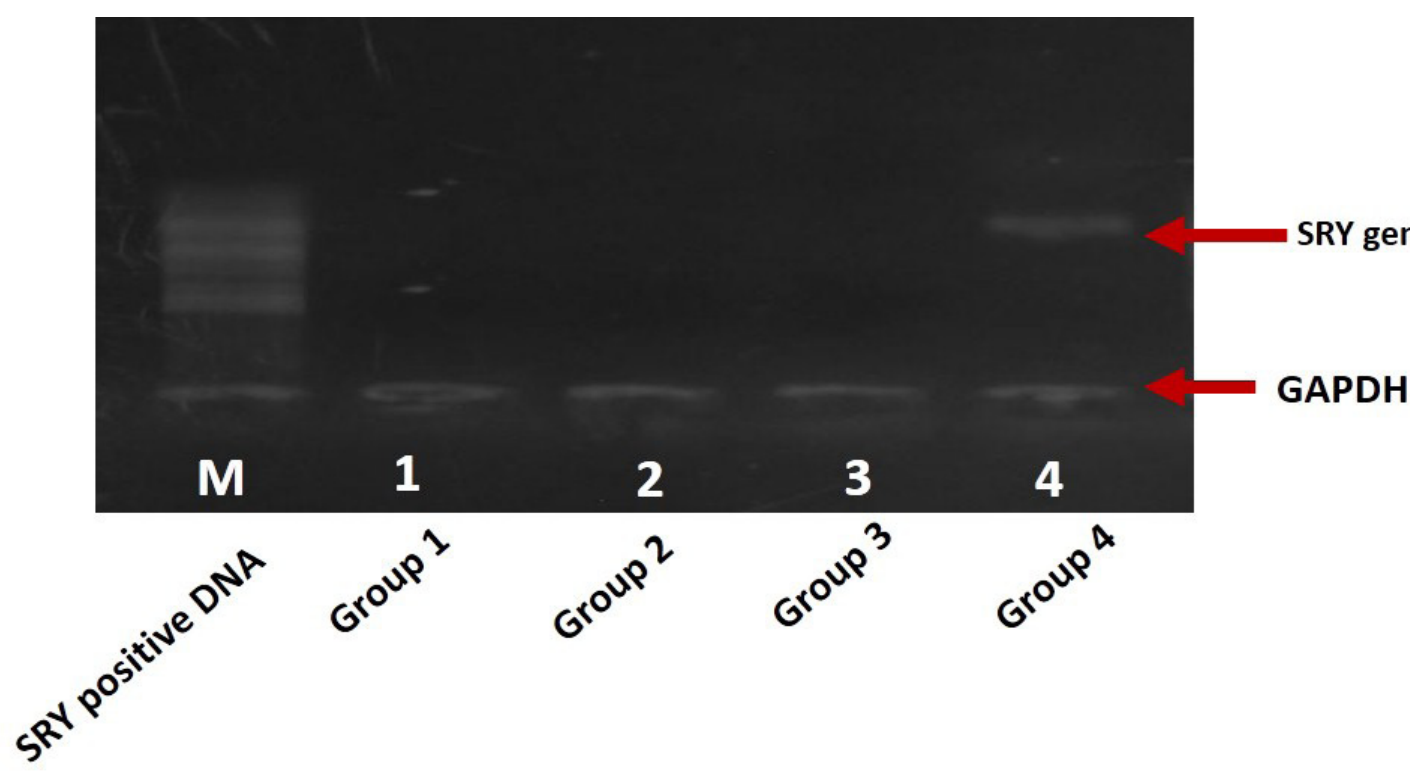

Fig. 7: An agrose gel electrophoresis for PCR products of SRY gene in the fundus of the stomach specimens of all groups. Lane M: SRY positive DNA marker.

Lanes 1, 2 and 3: Negative for SRY gene in groups 1, 2 and 3.

Lane 4: Positive for SRY gene in group 4 after three days from receiving male derived AD-MSCs. GADPH represent reference genes. 


\section{DISCUSSION}

Gastric ulcer associated with the excessive ingestion of aspirin is a major problem. Many factors such as gastric acid and pepsin secretion, gastric microcirculation, prostaglandin E2 (PGE2) content, proinflammatory cytokines; interleukin (IL)-1and tumor necrosis factor (TNF) play important roles in the genesis of gastric mucosal damage and subsequent development of ulcer ${ }^{[20,21]}$.

Adipose derived mesenchymal stem cells (ADMSCs) contains stem cells that can differentiate into osteogenic, chondrogenic, and adipogenic lineages. Many reports investigated their role in differentiation into myocytes, hepatocytes, neural cells and even epithelial cells of the lung, kidney and skin. These findings indicate that adipose tissue derived cells can be used in regenerative medicine and are considered as an attractive stem cell source for clinical applications ${ }^{[22]}$.

There is little information, however, about the therapeutic role of AD-MSCs in gastric disorders. Many studies have reported that BM-MSCs have a significant role in healing of gastric injuries ${ }^{[23,24]}$. Okamoto et al. reported that the healing capability of BM-MSCs was attributed to their ability to differentiate into gastric tissue elements as vascular endothelial cells, fundic epithelial cells as well as interstitial cells ${ }^{[25]}$.

Therefore, the current study aimed at demonstrating the therapeutic potential of adipose tissue-derived MSCs transplantation in accelerating healing of aspirin-induced gastric ulcer in albino rat, evidenced by histological and immunohistochemical examination.

In this study, three days after transplantation of ADMSCs (group 4), there was reepithelization in most areas of gastric mucosa with slight dilatation in the pits and lumina of the glands. Thus, the normal glandular architecture as well as normal appearance of oxyntic cells and parietal cells were restored. However, slight leucocytic infiltration in the corium of the mucosa was observed in this group compared with the ulcerinduced group (group 2).

A constant finding in this group was the distension of the surface epithelial cells and mucus neck cells with PAS positive mucus secretion. The mean value of optical density of PAS positive area in group 4 was significantly increase as compared to group 3 $(\mathrm{P}<0.05)$. This finding indicated complete regeneration of functioning surface mucus epithelial cells and mucus neck cells.

Similar findings were reported by Hyashi et al. who found that the damaged epithelia in the gastrointestinal mucosa was regenerated by bone marrow-derived $\operatorname{MSCs}^{[26]}$
Furthermore, many authors documented that the MSCs have phenotypes of interstitial lineage cells in the gastric wall. Indeed, minor population of MSCs could differentiate to smooth muscle cells and myofibroblasts in gastric wall. Thus, these differentiated cells of interstitial lineage can produce extracellular matrix that help in wound healing ${ }^{[27,28]}$.

Moreover, Askarov et al. reported that acceleration of ulcer regeneration by BM-MSCs transplantation was attributed to an increase in the levels of proinflammatory cytokines (IL-10, IL-4, transforming growth factorbeta (TGF- $\beta)$ ) with simultaneous reduction in the expression of apoptosis marker (caspase-9). So, BMMSCs could regulate the apoptosis activity in the gastric mucosa ${ }^{[29]}$.

In the present study, we evaluated the presence of adipose tissue derived stem cells in stomach tissue by using the chromosome Y (SRY gene) localization strategy. It was detected only in group 4 that received male derived AD-MSCs transplantation, indicating that they migrated to the local site of injury in the gastric mucosa.

Qing et al. reported that results showed that at 48 and 72 hours after BM-MSCs transplantation, the 5,6-carboxyfluorescein diacetate succinimidyl ester (CFDA-SE) labeled cells could be found in the injured gastric mucosa, while they were not detected in the gastric mucosa of rats received PBS only ${ }^{[30]}$.

Furthermore, we tried to trace the effect of in vitro expanded AD-MSCs on healing of GU by detecting the amount of CD44 positive cells in the basal parts of fundic glands. The total count of CD44 positive brownish cells showed significant increase in stem cells-treated $\mathrm{GU}$ as compared to untreated GU, $26.8 \pm 5.06$ vs $4.6 \pm 2.07(\mathrm{p}<0.05)$.

It was found that CD44 labels a population of small, undifferentiated cells in the isthmus of gastric glands. It was also expressed in the interglandular mesenchymal cells. However, in mice lacking CD44, the proliferation rate of stem cell niche was decreased dramatically, suggesting the role for CD44 in normal stem cell homeostasis ${ }^{[31]}$.

The MSC homing could be explained by the influence of different cytokines and growth factors. The inflammatory tissues release many cytokines such as IL-6, platelet-derived growth factor-BB (PDFG$\mathrm{BB}$ ) and Insulin-like growth factor 1 (IGF-1). Several studies have shown that these cytokines had an active role in the migration of $\mathrm{BM}-\mathrm{MSCs}^{[32]}$. However, CD44-HA interaction may have a more powerful force in guiding MSCs to migrate into the injured tissues ${ }^{[33]}$. This could be demonstrated by preincubation with an anti-CD44 blocking antibody thus, preventing the in vitro migration of $\mathrm{MSCs}^{[34]}$. 
After migrating to the injured area, the activated MSCs could potentially act like mini "bioreactors" in the injured area microenvironment by secreting growth factors and cytokines. The production of these soluble mediators by MSCs would be expected to complement endogenously produced growth factors and cytokines that regulate cellular processes such as chemotaxis, cell proliferation, cell signaling, extracellular matrix formation, and angiogenesis in the injured area ${ }^{[35]}$.

\section{CONCLUSION}

In conclusion, this study has shown that AD-MSCs were easily harvested, rapidly propagated in culture and were involved in the healing process of experimentallyinduced gastric ulcers in rats. It also showed the possibility of the use of AD-MSCs as a potential resource for clinical therapy of many gastrointestinal tract diseases. Accordingly, this study recommended the use of AD-MSCs as a new therapeutic modality in treatment of resistant gastrointestinal ulcers.

\section{CONFLICT OF INTEREST}

The authors have no conflicting financial interest.

\section{REFERENCES}

1. Chaturvedi A, Kumar MM, Bhawani G, Chaturvedi H, Kumar M and Goel KR. Effect of ethanolic extract of Eugenia Jambolana seeds on gastric ulceration and secretion in rats. Indian J physiol Pharmacol 2007; 51(2): 131-140.

2. Kalyanakrishnan F, Robert C. Peptic ulcer disease. Am Fam Physician 2007; 76(12): 1005-1013.

3. Cai S, García Rodríguez LA, Massó-González EL and Hernández-Díaz S. Uncomplicated peptic ulcer in the UK: trends from 1997 to 2005. Aliment Pharmacol Ther 2009; 30(10):1039-48.

4. Kang JM, Kim N, Kim B, Kim JH, Lee BY, Park JH, Lee MK, Lee HS, Kim JS, Jung HC, Song IS. Enhancement of Gastric Ulcer Healing and Angiogenesis by Cochinchina Momordica Seed Extract in Rats. J Korean Med Sci 2010; 25: 875-81.

5. Kumar D, Hegde HV, Patil PA, Subarna R, Kholkute SD. Antiulcer activity of water soaked Glycine max L. grains in aspirin induced model of gastric ulcer in Wistar rats. Journal of Ayurveda \& Integrative Medicine 2013; 4(3): 134-137.

6. Askarov MB, Onischenko NA. Multipotent mesenchymal stromal cells of autologous bone marrow stimulate neoangiogenesis, restore microcirculation, and promote healing of indolent ulcers of the stomach. Bull Exp Biol Med 2008; 146: 512-516.
7. Lopez JT, Hristov TG, García-Arranz M, GarcíaOlmo D. Stem cell therapy for digestive tract diseases: current state and future perspectives. Stem Cells and Development; 2010, 20(7): 1113-1129.

8. Gimble JM, Katz AJ and Bunnell BA. Adiposederived stem cells for regenerative medicine. Circ Res 2007;100 (9): 1249-60.

9. Kotton DN, Fine A. Lung stem cells. Cell Tissue Res 2008; 331, 145-156.

10. Zuk PA. The adipose-derived stem cell: Looking back and looking ahead. Mol Biol Cell 2010; 21:1783-7.

11. Hallgren R, Gerdin B, Tufveson G. Hyaluronic acid accumulation and redistribution in rejecting rat kidney graft. Relationship to the transplantation edema. J Exp Med 1990; 171: 2063-2076.

12. Naor D, Nedvetzki S, Golan I, Melnik L, Faitelson Y. CD44 in cancer. Crit Rev Clin Lab Sci 2002; 39: 527-579.

13. Khaldoyanidi S, Denzel A, Zoller M. Requirement for CD44 in proliferation and homing of hematopoietic precursor cells. J Leukoc Biol 1996; 60: 579-592.

14. Avigdor A, Goichberg P, Shivtiel S, Dar A, Peled A, Samira S, Kollet O, Hershkoviz R, Alon R, Hardan I, Ben-Hur H, Naor D, Nagler A, Lapidot T. CD44 and hyaluronic acid cooperate with SDF-1 in the trafficking of human CD34+ stem/progenitor cells to bone marrow. Blood 2004; 103: 2981-2989.

15. Liu Y, Zhang Z, Qin Y, Wu H, Lv Q, Chen X, Deng W..A new method for Schwann-like cell differentiation of adipose derived stem cells. Neuroscience Letters 2013; 551:79- 83 .

16. Ra JC, Shin IS, Kim SH, Kang SK, Kang BC, Lee HY, Kim YJ, Jo JY, Yoon EJ, Choi HJ, Kwon E. Safety of intravenous infusion of human adipose tissue-derived mesenchymal stem cells in animals and humans. Stem Cells and Development 2011; 20: 1297-1308.

17. Romano M, Meise KS , Souzzo R, Sessa G, Perisco M, Coffey RJ. Regional distribution of TGF $\alpha$ and EGF in normal and portal hypertensive gastric mucosa in humans. Dig Dis Sci 1996; 40: 263-67.

18. Li, HH, Fu XB, Ouyang YS, Cai CL, Wang J, Sun TZ. Adult Bone-marrow-derived mesenchymal stem cells contribute to wound healing of skin appendages. Cell Tissue Res 2006; 14:325-35

19. Cui KH, Warnes GM, Jeffrey R, Matthews CD. Sex determination of preimplantation embryos by human testis-determining-gene amplification. Lancet 1994; 343(8889):79-82 
20. Laine L, Takeuchi K, Tarnawski A. Gastric mucosal defense and cytoprotection: bench to bedside. Gastroenterology 2008; 135(1):41-60.

21. Wallace JL. Mechanisms, prevention and clinical implications of nonsteroidal anti-inflammatory drug-enteropathy. World J Gastroenterol 2013; 19(12):1861-1867.

22. Komori M, Tsuji S, Tsujii M, Murata H, Iijima H, Yasumaru M, Nishida T, Irie T, Kawano S and Hori M. Efficiency of bone marrow-derived cells in regeneration of the stomach after induction of ethanolinduced ulcers in rats. J Gastroenterol 2005; 40: 591599.

23. Andoh A, Bamba S, Fujiyama Y, Brittan M, Wright NA. Colonic subepithelial myofibroblasts in mucosal inflammation and repair: contribution of bone marrowderived stem cells to the gut regenerative response. J Gastroenterol 2005; 40: 1089-1099.

24. Hayashi Y, Tsuji S, Tsujii M, Nishida T, Ishii $S$, Nakamura T, Eguchi $H$, Kawano $S$. The transdifferentiation of bone-marrow-derived cells in colonic mucosal regeneration after dextran-sulfatesodium-induced colitis in mice. Pharmacology 2007; 80: 193-199.

25. Okamoto R, Yajima T, Yamazaki M, Kanai T, Mukai M, Okamoto S, Ikeda Y, Hibi T, Inazawa J, Watanabe M. Damaged epithelia regenerated by bone marrowderived cells in the human gastrointestinal tract. Nature Med 2002; 8:1011-7.

26. Hayashi Y, Tuji S, Tsujii M, Nishida T, Ishii S, Iijima H, Nakamura T, Eguchi H, Miyoshi E, Hayashi N, Kawano S. Topical transplantation of mesenchymal stem cells accelerates gastric ulcer healing in rats. Am J Physiol Gastrointest Liver Physiol 2008; 294: 778786.

27. Tarnawski AS. Cellular and molecular mechanisms of gastrointestinal ulcer healing. Dig Dis Sci 2005; 50 (1): 24-33.

28. Nishida T, Tsuji S, Kimura A, Tsujii M, Ishii S, Yoshio T, Shinzaki S, Egawa S, Irie T, Yasumaru M, Iijima H, Murata H, Kawano S, Hayashi N. Endothelin-1, an ulcer inducer, promotes gastric ulcer healing via mobilizing gastric myofibroblasts and stimulates production of stroma-derived factors. Am J Physiol Gastrointest Liver Physiol 2006; 290: 1041-1050.

29. Askarov MB, Vostrikova FO, Vorobjova NN, Onishenko NA. Effects of Autologous Bone Marrow Cells on Apoptosis and Regeneration of Non-Healing Autoimmune Gastric Ulcers. Bulletin of Experimental Biology and Medicine 2008;146 (11):585-590.

30. Qing C, Li Y, Chang-zheng W, Wen-hui Z, Ya-zhuo HU, Ben-yan WU. In vivo transplantation of bone marrow mesenchymal stem cells accelerates repair of injured gastric mucosa in rats. Chinese Medical Journal 2012;125(6):1169-1174.

31. Khurana SS, Riehl TE, Benjamin D. Moore BD, Fassan M, Rugge M, Romero-Gallo J, Noto J, Peek RM, Stenson WF, Mills JC. The Hyaluronic acid receptor CD44 coordinates normal and metaplastic gastric epithelial progenitor cell proliferation. The Journal of Biological Chemistry 2013; 288: 1608516097.

32. Kholodenko IV, Konieva AA, Kholodenko RV, Yarygin KN. Molecular mechanisms of migration and homing of intravenously transplanted mesenchymal stem cells. Journal of Regenerative Medicine \& Tissue Engineering 2013;1218.

33. Zhu H, Mitsuhashi N, Klein A, Barsky LW, Weinberg K, Barr ML, Demetriou A, Wu GD. The role of the hyaluronan receptor CD44 in MSC migration in the extracellular matrix. Stem cells 2006; 24:928-935.

34. Herrera MB, Bussolati B, Bruno S, Morando L, Mauriello-Romanazzi G, Sanavio F, Stamenkovic I, Biancone L, Camussi G. Exogenous mesenchymal stem cells localize to the kidney by means of CD44 following acute tubular injury. Kidney International 2007; 72: 430-441.

35. Chen X, Li Y, Wang L, Katakowski M, Zhang L, Chen J, Xu Y, Gautam SC, Chopp M. Ischemic rat brain extracts induce human marrow stromal cell growth factor production. Neuropathology 2002; 22 (4): 275-9. 